\title{
The cultivation of students' aesthetic ability in vocal music teaching Li Nian ${ }^{1,}$ Fei Wang ${ }^{2, b}$ \\ ${ }^{1}$ School of music and dance, Qujing Normal University, Qujing 655011, China \\ ${ }^{2}$ Faculty of education, Qujing Normal University, Qujing 655011, China \\ ani_anli@126.combwan_yifei@163.com
}

Keywords: vocal music teaching; aesthetic ability; training; advantage; way

\begin{abstract}
In the process of teaching, students should study not only professional knowledge, more important is to cultivate their aesthetic ability, only cultivate this ability, students can learn in regardless of what access to data can take the essence to its dregs, make up a level of learning. Many people may think, the vocal music class, as long as the students can learn the basic skills, so this course they can say is the pretty close, this inherently wrong idea is not only in the classroom, we must through the essence of teaching to change the concept of people. In the cultivation of aesthetic ability in classroom is not only to allow students to learn vocal music more smoothly, but also to help students in learning and life each aspect in the vision of a more unique, to learn things and the application of knowledge can let a person shine at the moment, is of great benefit to the development of students. This article focuses on the cultivation of students' aesthetic ability in vocal music teaching.
\end{abstract}

\section{Introduction}

The words we hear often aesthetic ability in daily life, generally used to evaluate the human eye, is more used in the ability of people to choose from things, so few people have aesthetic ability and vocal learning together, aesthetic ability is actually more abstract words, it can be used in the selection of specific the object, can also be used to describe a personal view of abstract things vision, the ability to distinguish right from wrong, only the aesthetic ability of figurative and abstract culture are good people can show good aesthetic ability, aesthetic ability and figurative by cultivating abstract aesthetic ability is cultivated, but abstract the aesthetic ability is very difficult through the ability to improve the aesthetic and improve, cultivate students' aesthetic ability in the vocal music teaching, is in training As long as they are able to do this, they will be able to become an aesthetic person. The following is a detailed description of the advantages and methods of cultivating students' aesthetic ability.

\section{The advantages of cultivating students' aesthetic ability in vocal music teaching}

No training in the teaching of vocal music aesthetic ability is noticed by many people because they do not fully understand the advantages of cultivating students' aesthetic ability in the vocal music teaching, if we do not waste time, and can not bring us any good, believe that we do not have much interest in this matter and let the teachers pay attention to cultivating students' aesthetic ability in the vocal music teaching, so that they understand the essential advantages, only to let them see the corresponding benefits, they will be willing to pay the hard work and effort. For the advantages of cultivating students' aesthetic ability in the teaching of vocal music, as has been mentioned, but not too much force, for the teacher's heart is not a word or two, how much convincing, so we will illustrate some of the advantages, can make teachers and students can accept, let them cooperate with each other to develop the required the aesthetic ability.

1.To enable students to learn more smoothly

In the vocal music classroom learning, students are not dependent on teachers, there are a lot of the time they are through their own efforts to practice and improve themselves, we will find that some 
students in autonomous learning, their learning efficiency and other students a lot of difference, this is not just because the students have talent different, but because they are looking for reference does not accord with what they want to learn the content, this is due in part to the aesthetic ability of the students have problems, they don't know what kind of information is really suitable for them, to help them to learn. We all know that this kind of vocal personal feelings strong discipline has a lot of uneven information to students, students' aesthetic ability if there is a problem, they will probably be something wrong to mislead, students now just when looking for a reference a little problem, when they need more students from the identity. When their autonomous learning, they may make big mistakes, serious or even mislead the student's life, so in today's learning to cultivate students' aesthetic ability to let them find in autonomous learning for their own good, some guidance, can let students learn faster, let them learn more smoothly, if students find the correct guidance in autonomous learning, they can learn many detours, can help them Establish confidence in learning. The vocal music teaching, cultivate students' aesthetic ability, can make their learning more smoothly, to help students in this subject made great progress, ignore this point will not only cause immediate small losses, will have a greater loss to other students, and then think of culture will spend a lot of time.[1]

2. To enable students to benefit from future learning

Vocal learning will be accompanied by the growth of the students in the whole process, not only the students will be used in the work, influence of various knowledge in their lives and ultimately extending from the vocal music, in the process of growing up, the vocal music aesthetic ability can directly determine the students in this aspect of the achievement and understanding, aesthetic ability is insufficient to to bring the students a lot of obstacles in vocal music learning, such as unable to find a good part of every hue from vocal music, vocal music or even can not distinguish. Vocal music is an advanced art, if students' aesthetic ability is not enough to distinguish between good and popular literature or art from the student, accompanied by their own mistakes has been extended to the students' work and life, cultivate the aesthetic idea is not only to make the students improve their learning of vocal music in this course, the students of other disciplines the study also has an irreplaceable role, along with the advent of the information society, information and learning materials are uneven in quality, if not all students' aesthetic ability, to find the zhaodanquanshou, not only can not help their own learning, but also to make their step back, give students thought cast dust. The aesthetic concept can determine a person's world outlook and values to a great extent, and vocal exercises and learning are the students an aesthetic concept of a great opportunity in this course, students will benefit a lot, their progress is obviously the vocal music. In the study of vocal music training students' aesthetic concept, can make students learn a lot in the future, can change their life trajectory, have a great impact on their lives.[2]

\section{Vocal music teaching students aesthetic ability training mode}

In the vocal music teaching to cultivate students' aesthetic ability has many benefits, we mentioned here is only a drop in the bucket, the teachers are also aware of this, try to use their own efforts and ways to help students to cultivate the correct aesthetic standards, but did not see the effect, some teachers may think that the development of self comfort, aesthetic effect the ability of students in favor of students after one thirty, while not manifest is a normal thing, in fact, although the cultivation of the aesthetic ability plays an important role in the future development of the students, but that does not mean there is no effect on the students' current situation, did not see the effect of teacher training, the main reason is that their way of training is out of the question, the students' aesthetic ability has not been developed, so what's the right thing to do for cultivation of aesthetic ability Style?[3]

\section{To give students different works for students to observe}

Each expert's works and to identify and not because of their theoretical learning reach the acme of perfection, but because they have so much, to the point out works in the face of a variety of works or vocal learning in the cultivation of students' aesthetic ability is no exception, in this process, the teacher is not only to pass the theory of indoctrination to let students learn to distinguish the work or 
data quality, but to give them enough choice, let them see some more work, after the good and bad for them to experience, they will be able to gradually have some accumulation, the best way is to let the students to observe the students' different works. In class, teachers can find some different types and styles of works, mixed together, let students experience and identify, at the beginning of the students without any basis, teachers can find some quality are relatively large works, so that students can have a little heart to find out, to establish their own confidence. After the students are familiar with, teachers can take different degrees of slightly lower, let students improve their ability to distinguish to identify, this practice can effectively improve students' aesthetic ability, they can be more skilled enough, in the course of their own learning but also to have the ability to discriminate between good and bad, let them learn more smoothly. Some teachers worry about some delivery error values work on the table for students tasting may not be appropriate, if there is what error will let the students on the wrong road more walk more far, for this concern, teachers can cultivate their aesthetic ability at the same time, the number of good works less, and these works do not say clearly where to students, analyzing the advantages and disadvantages, so they can avoid these bad works, make their own aesthetic ability to progress in the right direction. For students of different works allow students and teachers to spend some effort to find these works to be seen, although have a little hard, but the rewards will let the teachers be startled at, was able to see the students' aesthetic ability, the teacher can give great comfort.[4]

2. Let the students say what they think about the work

In the tasting of these different works, teachers can not let students take all the views and opinions are put in the heart - not to mention, it may be able to avoid some embarrassment, but definitely not a permanent solution, because the teacher did not know the students' mind, don't know what they think about in good works, but do not know them for some wrong work whether can understand where is wrong, the teachers give their explanations they may know why so bad, but their original thinking may not be the case, perhaps after they heard the teacher explain did not solve their doubts, perhaps the ideas of students than teachers can be more intuitive, interpretation let us know more distinctive works of quality, so let the students develop an idea of how good they are not hidden in the heart A method of aesthetic ability. Teachers should allow them to express their views, one can learn from some say students with good ideas to help students understand, on the other hand, can see how the basic skills of students' aesthetic ability, for teachers to cultivate students' aesthetic ability. There are many teachers think that some bad tasting works really hard to get in good taste, all these words naked out will cause bad effects on the classroom, actually not, some knowledge of students and teachers know knows, and hide not discussed, rather than take the wrong views openly are on the table for everyone to learn knowledge from these analyses, the wrong point of view, to draw their own aesthetic ability and these works can never, let the students have a bottom line, help them to better cultivate their aesthetic ability. It is one of the ways for students to express their ideas about the work, which can make the students improve their aesthetic ability. It can make the students listen to each other's views and have more ideas.[5]

3. Let the students choose the skills they want to learn

Vocal learning is varied, every technique is very attractive for students, but we can't put all to teach students and cultivate a lot of vocal to the skills and knowledge of students' aesthetic ability and not much help, and some will even let the students' aesthetic ability of the original and this technique produces contradictions and conflicts, let students feel confused in the process of the cultivation of the aesthetic ability, teachers can make students to choose learning skills, specially selected a lesson to tell the students they chose these skills to learn the pros, let students see both sides of the coin, so he did not go to school to learn in the classroom skills in students, the heart can be prepared, the bad side down, so that the aesthetic ability of the students in the teacher's help They will be able to make progress in their learning process. Let the students choose their own love, want to learn the skills and not allow teachers to put all these works to teach students, but let the teacher see factors of students' aesthetic ability in the future learning of middle school students may be affected by these factors, to help them on their impact to a minimum.

\section{To correct students' mistakes}


As already mentioned, influenced by the ideas for some bad tasting works may make students, we also said to allow teachers to correct the students' mistakes of thought, let them keep the right thought in the process of cultivating aesthetic ideas, some teachers do so, but some students find aesthetic ideas by these good works have great influence, teachers might think this is because the students repeat, but in my opinion, teachers have a large part of the responsibility to correct the students' mistakes, the teacher's voice is serious enough, can make the students realize that the same mistake is not repeated, the teacher 's words can cause the attention of the students, if not corrected in these two points, then the students would not be aware of the seriousness of the problem, for this mistake A guard, which is why their aesthetic ability is high or low, can never increase to a fixed level, teachers must correct the students' mistakes in the meaning of words, whether a teacher's teaching style is usually tough or gentle, in the face of errors must be strict enough, let students understand the key the problem, so that they can do see the same problem at the next time to avoid, so it can ensure that the students have been brought up the idea of what will not be pulled down. To correct the students' mistakes is the key to strictly maintain the aesthetic ability of the students, or what is the cultivation of students ability no matter how good, how to improve quickly, ultimately unable to maintain, to pay the teachers and the students efforts will be wasted.[6]

\section{Summary}

On the cultivation of students' aesthetic ability in the vocal music teaching is of great significance to them, as long as they are in the process of cultivating their aesthetic ability, be able to make their own learning, life and work are more excellent, so that they can see in learning vocal music aesthetic ability to foster their benefits. In the process of training teachers must be strong enough to let the students' aesthetic ability can be cultivated, and can permanently maintain or even enhance.

\section{References}

[1]Countryman J, Gabriel M, Thompson K. Children's spontaneous vocalisations during play: aesthetic dimensions[J]. Music Education Research, 2016, 18(1):1-19.

[2]Gu M D. The Ethical Turn in Aesthetic Education: Early Chinese Thinkers on Music and Arts[J]. Journal of Aesthetic Education, 2016, 50(1):95.

[3]Howard K. Songs of Seoul: An Ethnography of Voice and Voicing in Christian South Korea by Nicholas Harkness. : Berkeley: University of California Press, 2014. 320 pp.[J]. Journal of Korean Studies, 2016, 21(3):599 - 631.

[4]Tinius J. Institutional Formations and Artistic Critique in German Ensemble Theatre[J]. Performance Research, 2015, 20(4):71-77.

[5]Huang D, Wang R, Yang S. Cogels of Hyaluronic Acid and Acellular Matrix for Cultivation of Adipose-Derived Stem Cells: Potential Application for Vocal Fold Tissue Engineering[J]. Biomed Research International, 2016, 2016(18):1-10.

[6]Norton N, Ginsborg J, Greasley A. Health Education in Instrumental/Vocal Music Lessons: The Teacher's Perspective[C]// International Society for Music Education. 2014. 